Research, Society and Development, v. 9, n. 10, e2819108428, 2020

(CC BY 4.0) | ISSN 2525-3409 | DOI: http://dx.doi.org/10.33448/rsd-v9i10.8428

\title{
A implantação do CEFET/campus Nova Friburgo: um marco para a formação profissional e tecnológica na região
}

\section{The implementation of CEFET/campus Nova Friburgo: a landmark for technological professional training in the region \\ La implementación del CEFET/campus Nova Friburgo: um hito para la formación profesional tecnológica em La región}

Recebido: 13/09/2020 | Revisado: 14/09/2020 |Aceito: 24/09/2020 | Publicado: 26/09/2020

\section{Júlia Cristina Eyer de Mello}

ORCID: https://orcid.org/0000-0002-5277-2745 Centro Federal de Educação Tecnológica Celso Suckow da Fonseca, Brasil E-mail: Julia.eyer@outlook.com

Marta Ferreira Abdala Mendes ORCID: https://orcid.org/0000-0001-5573-4317 Instituto Federal do Rio de Janeiro, Brasil E-mail: marta.mendes@ifrj.edu.br

\section{Resumo}

O Centro Federal de Educação Tecnológica Celso Suckow da Fonseca - CEFET/ RJ, ao longo de sua existência de cento e três anos, consolida-se como uma das principais instituições de ensino público Federal do Brasil. Sua trajetória tem sido marcante para o cenário da educação profissional e tecnológica com importante responsabilidade na qualificação para além da atuação no mundo do trabalho. No palco da reconstituição da memória e no curso do processo de expansões ocorridas na instituição, o presente trabalho tem como objetivo ressaltar a implantação do CEFET campus Nova Friburgo/RJ e sua importância para o desenvolvimento e qualificação profissional da região com ofertas de cursos de graduação, pós-graduação e ensino médio integrado, dando oportunidades para os jovens da cidade e região a uma educação de qualidade. Sob o foco histórico-descritivo, procuramos resgatar alguns dos muitos momentos históricos vividos por essa instituição centenária, revisitar a trajetória da implantação do CEFET para o interior do Estado do Rio de Janeiro e discorrer sobre as atividades desenvolvidas no campus Nova Friburgo. Este trabalho é resultado de uma pesquisa bibliográfica e documental na qual foram levantadas obras que serviram de sustentação às ideias que se pretende expor. Como resultado das análises, 
verificamos que o CEFET/ Nova Friburgo é um marco importante na interiorização para a formação profissional e tecnológica, sem perder de vista a dinâmica do desenvolvimento da região. Além disso, as expansões dos diversos campi orientados pelo conceito de cidade polo devem aproveitar o potencial de desenvolvimento à possibilidade de parcerias e infraestrutura existente, e que o processo de constituição da história do CEFET, particularmente o campus Nova Friburgo, é carregado de singularidade, sentidos e significados.

Palavras-chave: Memória histórica; CEFET/campus Nova Friburgo; Educação profissional e tecnológica.

\section{Abstract}

The Federal Center for Technological Education Celso Suckow da Fonseca - CEFET / RJ, throughout its existence of more than one hundred years, has consolidated itself as one of the main Federal public education institutions in Brazil. Its trajectory has been remarkable for the scenario of technological professional education with an important responsibility in qualification beyond the performance in the world of work. On the stage of memory reconstruction and in the course of the expansion process that took place at the Institution, the present work aims to highlight the implementation of the CEFET Nova Friburgo campus and its importance for the development of the region with offers of undergraduate, graduate and integrated high school, providing quality education to young people in the city and region. Under the historical-descriptive focus, we seek to rescue some of the many historical moments experienced by this centenary institution, revisit the trajectory of the implementation of CEFET in the interior of the State of Rio de Janeiro and discuss the activities developed on the Nova Friburgo campus. This work is the result of a bibliographic and documentary research in which works were raised that served to support the ideas that are intended to be exposed. As a result of the analysis, we found that CEFET / Nova Friburgo is an important milestone in the interiorization for technological professional training, without losing sight of the region's development dynamics. In addition, the expansions of the various campuses guided by the concept of a pole city should take advantage of the potential for development to the possibility of partnerships and existing infrastructure, and that the process of constituting the history of CEFET, particularly the Nova Friburgo campus, is charged with singularity, senses and meanings.

Keywords: Historical memory; CEFET/ Nova Friburgo campus; Professional and technological education. 


\section{Resumen}

El Centro Federal de Educación Tecnológica Celso Suckow da Fonseca - CEFET / RJ, a lo largo de su existencia de más de cien años, se ha consolidado como una de las principales instituciones federales de educación pública en Brasil. Su trayectoria ha sido notable por el escenario de la formación profesional tecnológica con una importante responsabilidad en la calificación más allá del desempeño en el mundo laboral. En la etapa de reconstrucción de la memoria y en el transcurso del proceso de expansión que se desarrolló en la Institución, el presente trabajo tiene como objetivo resaltar la implementación del campus CEFET Nova Friburgo y su importancia para el desarrollo de la región con ofertas de pregrado, posgrado y Bachillerato integrado, brindando educación de calidad a los jóvenes de la ciudad y región. Bajo el enfoque histórico-descriptivo, buscamos rescatar algunos de los múltiples momentos históricos vividos por esta institución centenaria, repasar la trayectoria de la implementación del CEFET en el interior del Estado de Río de Janeiro y discutir las actividades desarrolladas en el campus de Nova Friburgo. Este trabajo es el resultado de una investigación bibliográfica y documental en la que se plantearon trabajos que sirvieron para sustentar las ideas que se pretenden exponer. Como resultado del análisis, encontramos que CEFET / Nova Friburgo es un hito importante en la interiorización de la formación profesional tecnológica, sin perder de vista la dinámica de desarrollo de la región. Además, las ampliaciones de los distintos campus guiadas por el concepto de ciudad polo deben aprovechar el potencial de desarrollo a la posibilidad de alianzas e infraestructura existente, y que el proceso de constitución de la historia del CEFET, en particular el campus de Nova Friburgo, esté cargado de singularidad, sentidos y significados.

Palabras clave: Memoria historica; CEFET / campus Nova Friburgo; Educación profesional y tecnológica.

\section{Introdução}

No presente artigo, procuramos traçar as relações entre história e memória do Centro Federal de Educação Tecnológica Celso Suckow da Fonseca CEFET/RJ, identificando as motivações e os limites que permitiram a criação de uma escola-modelo, inicialmente para formar professores para o ensino técnico e que, depois, foi se transformando para formar mão de obra técnica qualificada, através de um ensino tecnológico de excelência e destacar a importância da preservação da memória institucional para consolidação de sua identidade e de fortalecimento de seus valores e tradições. O reconhecimento do patrimônio institucional nos 
ajuda a (re) configurar a imagem de uma instituição segundo: sua herança material, imaterial e cultural (Candau, 2011). Nesse sentido, refletimos sobre a história e trajetória dessa instituição centenária para compreender sua "memória voltada a realidade anterior, a anterioridade que constitui a marca temporal da coisa 'lembrada', do 'lembrado' como tal" (Ricoeur, 2007, p.26).

$\mathrm{Na}$ atualização da memória histórica, buscamos trabalhar com imagens a partir do acervo fotográfico do CEFET/RJ, para ilustrar e definir temporalmente a sua trajetória, pois segundo Ciavatta (2004):

As fotografias são mundo de relações silenciosas, densas congeladas no tempo mínimo do obturador. Mundos de seres calados e imóveis que devem ser decifrados a partir do contexto onde se encontram na história de sua relação com os demais seres, tanto pessoas quanto objetos (Ciavatta, 2004, p.45).

Especificamente, a escolha pelo estudo da história e memória do CEFET campus Nova Friburgo se justifica devido a sua importância para o desenvolvimento social e econômico da cidade e região, ao oferecer aos jovens uma educação profissional humana e integrada, como forma de acesso ao conhecimento, à cultura, à ciência e ao trabalho (Ramos, 2008).

\section{Metodologia}

Para alcançar os objetivos deste trabalho realizamos um estudo de cunho qualitativo, pois conforme descreve Minayo (2010), o método qualitativo da pesquisa:

É o que se aplica ao estudo da história, das relações, das representações, das crenças, das percepções e das opiniões, produtos das interpretações que os humanos fazem a respeito de como vivem, constroem seus artefatos e a si mesmos, sentem e pensam (Minayo, 2010, p. 57).

O estudo foi construído a partir de uma discussão teórica pautada metodologicamente em uma revisão bibliográfica que de acordo com Medeiros (2000), promove a reflexão sistemática e o levantamento de informações com o conhecimento já adquirido, e para aprofundarmos a nossa investigação foi realizada uma análise documental nos registros da Instituição que serviu para o fortalecimento da fundamentação do trabalho, pois segundo Medeiros, “a pesquisa documental compreende o levantamento de documentos que podem ser 
(CC BY 4.0) | ISSN 2525-3409 | DOI: http://dx.doi.org/10.33448/rsd-v9i10.8428

encontrados em arquivos públicos, em arquivos de entidades educacionais e/ou científicas, em arquivos de instituições religiosas, museus, memórias, fotografias . . ." (Medeiros, 2000, p.37).

Baseamos a perspectiva da memória e identidade organizacional do CEFET campus Nova Friburgo, segundo os autores, Ciavatta (2004; 2005); Ricoeur (2007); Ramos (2002; 2008); Brandão (2009); Le Goff (1990); Candau (2011).

\section{Centro Federal de Educação Tecnológica Celso Suckow da Fonseca (CEFET/RJ): Uma Instituição Centenária}

A identidade do CEFET foi construída ao longo de uma trajetória que remonta à origem do ensino profissionalizante no Brasil. Foi a partir do Decreto $\mathrm{n}^{\circ} 1.880$, de 11 de agosto de 1917 que se iniciou a história do CEFET/RJ. Inicialmente criado como Escola Normal de Artes e Ofícios Wenceslau Braz, localizada no Rio de Janeiro (antigo Distrito Federal) à Rua General Carrabaro n 338 no bairro do Maracanã, caracterizou-se por ser a única escola pública voltada para formação de docentes habilitados a lecionarem nas escolas de aprendizes e artífices, atendendo assim à crescente urbanização e desenvolvimento industrial do país do início do século XX. O artigo $1^{\circ}$ do referido Decreto apontava os propósitos para criação da Escola Normal de Artes e Ofícios e definia que: "Para instrução e preparo dos professores, mestres e contramestres dos vários institutos e escolas profissionais do Distrito federal, assim como de professores de trabalhos manuais para as escolas primárias". 
Figura1 - Fachada da Escola Normal de Artes e Ofícios Wenceslau Braz - 1917

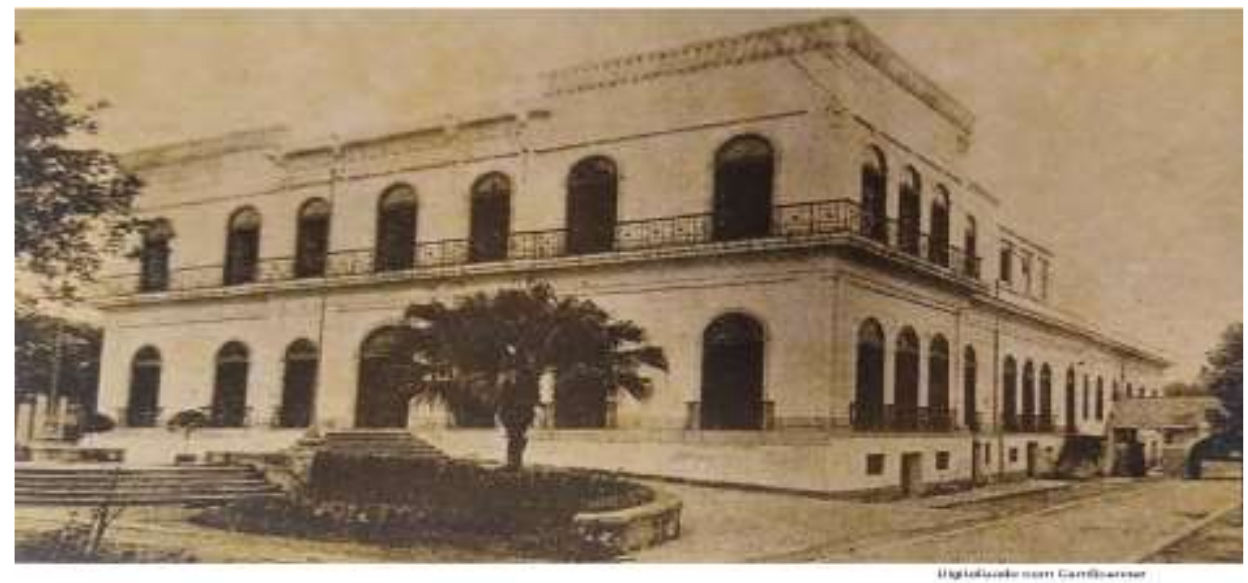

Fonte: Registro de uma Instituição Centenária CEFET/RJ (Pastore; Devonish; Cardoso, 2017). ${ }^{1}$

Tendo sido criada com objetivo específico desde o início de sua fundação, a Escola Normal de Artes e Ofícios Wenceslau Braz tinha características que a distinguia. Aos seus alunos era exigido, para o ingresso, o curso primário e a maioria dos seus professores tinha curso superior. O objetivo institucional era formar profissionais mais voltados para a modernização da indústria, que começava a ser implantada no país. Segundo Cardoso (2000), a escola Normal de Artes e Ofícios Wenceslau Braz iniciou suas atividades oferecendo basicamente dois cursos: o Curso Técnico Profissional frequentado por alunos para trabalhos em madeira e metal (carpintaria, marcenaria, tornearia, serralheiro, ferreiro, dentre outros) e Curso de trabalhos Manuais, predominantemente formado por alunas, com oficinas de chapéus, costura e economia doméstica. Sendo, portanto uma escola mista desde a sua fundação.

\footnotetext{
${ }^{1}$ Livro publicado em comemoração ao centenário do CEFET/RJ, citado nas referências.
} 
Research, Society and Development, v. 9, n. 10, e2819108428, 2020

(CC BY 4.0) | ISSN 2525-3409 | DOI: http://dx.doi.org/10.33448/rsd-v9i10.8428

Figura 2 - Atividades das oficinas femininas - aula de costura e bordado.

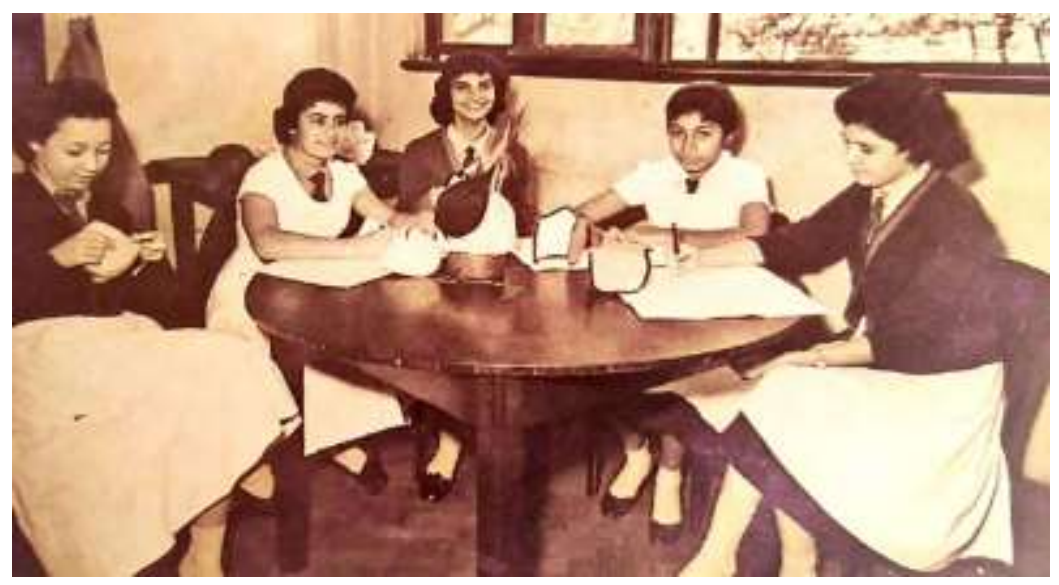

Fonte: Registro de uma Instituição Centenária CEFET/RJ (Pastore; Devonish; Cardoso, 2017).

As oficinas femininas ocuparam um lugar de destaque por acompanharem a inclusão das mulheres na vida profissional, conforme ressalta Cardoso (2005), novos espaços sociais e profissionais eram por elas conquistados, apesar das resistências encontradas, como mostram artigos da imprensa advertindo para o perigo da emancipação feminina.

Em função da industrialização brasileira impulsionada durante o governo Vargas, a Educação Profissional passou a ter um maior destaque para atender ao capital industrial com a formação de uma mão de obra qualificada a fim desempenhar as novas demandas de modernização do Brasil. Com isso, a Escola Normal de Artes e Ofícios Wenceslau Braz não atendia mais as novas expectativas do país. O governo federal decidiu pelo fechamento da Escola, e em 1937 o seu prédio foi derrubado e construído no mesmo local a Escola Técnica Nacional (ETN), dentro de um modelo de formação de artífices, mestres e técnicos para a indústria nacional e não mais para preparar docentes para o ensino industrial. 
Figura 3 - Inauguração da ETN pelo Presidente Getúlio Vargas em 07/10/1944.

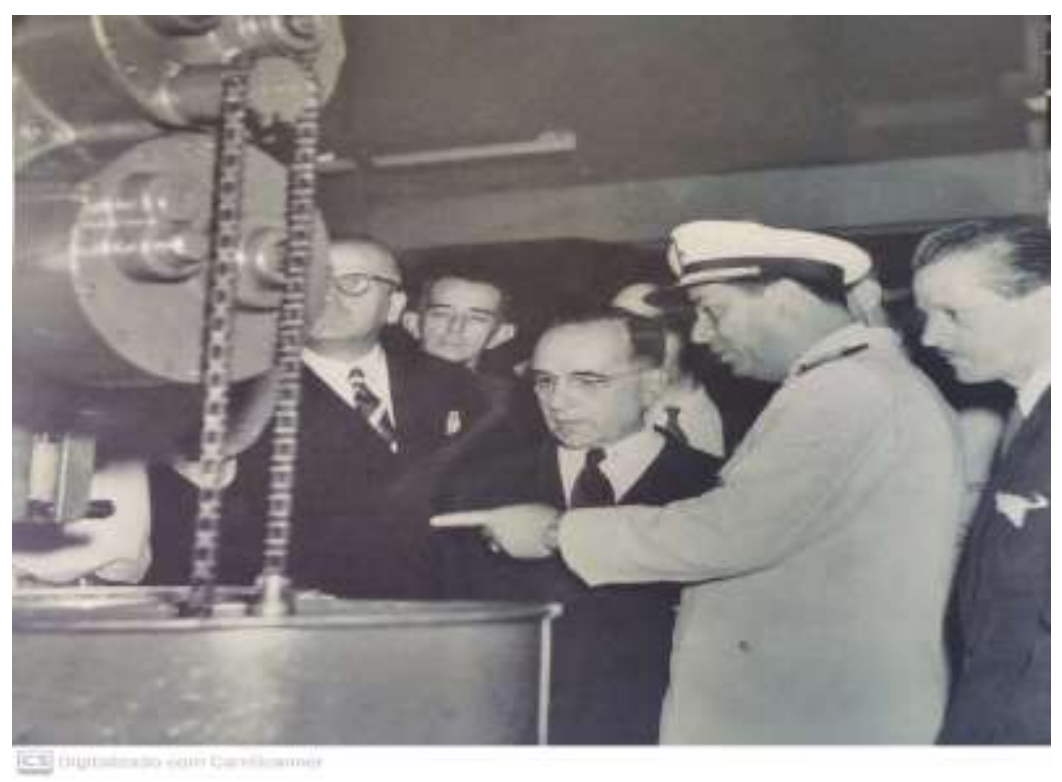

Fonte: Registro de uma Instituição Centenária CEFET/RJ (Pastore; Devonish; Cardoso, 2017).

Um novo capítulo se descortinou na história da Instituição, pelo Decreto-Lei $n^{\circ} 4.127$, de 25 de fevereiro de 1942, que estabeleceu as bases de organização da rede federal de estabelecimentos de ensino industrial. Por se localizar na capital do país, a ETN seria um modelo nacional, assim como o Colégio Pedro II e o Instituto de Educação, com a oferta de formação em dois níveis: cursos industriais básicos e cursos industriais técnicos. De acordo com Pastore; Devonish ; Cardoso (2017), em 1945 a ETN contava com 15 cursos industriais: Mecânica de Máquinas, Mecânica de Precisão, Fundição, Serralheria e Forja, Mecânica de Automóveis, Aparelhos Elétricos e Telecomunicações, Alfaiataria, Corte e Costura, Chapéus Flores e Ornatos, Carpintaria, Marcenaria, Cerâmica, Tipografia e Encadernação.

Em agosto de 1965, através da Lei ${ }^{\circ}$ 4.759, a Escola Técnica Nacional passou a ser chamada Escola Técnica Federal da Guanabara (ETFG), devido à mudança da capital para Brasília. Em 1966, a ETFG implantou o curso de Engenharia de Operação, de nível superior de curta duração, destinados à formação de profissionais para a indústria. Realizados em convênio com a Universidade Federal do Rio de Janeiro (UFRJ) para efeito de colaboração do corpo docente e expedição de diplomas, os cursos atendiam as seguintes especialidades: Engenharia de Operação Elétrica, Engenharia de Operação Eletrônica e Engenharia de Operação Mecânica. (Dias, 1973).

Novamente a escola teve seu nome alterado, através do Decreto-Lei n 181 , de 17 de fevereiro de 1967, para Escola Técnica Federal Celso Suckow da Fonseca, em homenagem a 
seu diretor e também professor, falecido em $1966 .^{2}$ Com o grande crescimento das atividades da escola e já sendo reconhecida como referência nacional na formação de técnicos de alto nível, o governo federal implantou na instituição, em 1971, um Centro de Treinamento para Professores que contou com o apoio de consultores especializados em Educação, fruto de um convênio com o Centro de Treinamento com o Estado da Guanabara (CETEG) e com o Centro de Treinamento de Formação de Mão de Obra (CENAFOR), a fim de preparar professores para disciplinas específicas dos cursos técnicos e dos cursos de Engenharia de Operação. (Brandão, 2009).

Com o objetivo de proporcionar a integração vertical entre os diversos níveis de formação técnica, o governo federal transformou as Escolas Técnicas Federais do Rio de Janeiro, de Minas Gerais e do Paraná em Centros Federais de Educação Tecnológica (CEFET), obtendo com esta medida a otimização dos recursos humanos e materiais já existentes em tais instituições, cabendo ainda aos CEFET à tarefa de qualificar professores para a eficiente atuação nos diversos graus do ensino tecnológico do país. Dessa forma, em 1978, com a Lei ${ }^{\circ} 6.545$ a Escola Técnica Celso Suckow da Fonseca tornou-se o Centro Federal de Educação Tecnológica Celso Suckow da Fonseca, uma instituição de educação superior, uma autarquia de regime especial, vinculada ao Ministério da Educação (MEC), com oferta de cursos de nível médio, graduação e pós-graduação, licenciatura plena e curta, atividades de extensão e de pesquisa na área profissional e tecnológica.

Durante os governos dos presidentes Fernando Collor de Mello (1990-1992), Itamar Franco (1992-1995) e, depois Fernando Henrique Cardoso (1995-2002), as políticas neoliberais foram referenciais centrais na formulação de políticas públicas para a educação pelo Estado brasileiro. A partir de 1988, em função da reforma do ensino médio e técnico, promovida pelo Decreto ${ }^{\circ}$ 2.208/97, o CEFET/RJ deixou de oferecer cursos técnicos de nível médio na forma integrada, passando a oferecer, separadamente, o ensino médio da educação profissional de nível técnico. No governo de Luís Inácio Lula da Silva (2003-2010), o decreto que dispôs sobre a separação do ensino médio, técnico e profissional foi revogado e o novo Decreto $\mathrm{n}^{\circ} 5.154 / 2004$ facultou às instituições de ensino profissional do país oferecer, além

\footnotetext{
${ }^{2}$ Sobre o engenheiro e educador Celso Suckow da Fonseca cabe destacar que foi referência nacional quanto ao ensino profissionalizante industrial, tendo publicado importante material sobre a história desse ensino no Brasil. É importante frisar também, que Celso Suckow da Fonseca foi Diretor da ETN por três mandatos: de 1943 a 1951, de 1960 a 1963 e de 1963 a 1966 e professor concursado de Desenho Técnico na Escola Técnica Nacional de 1951 a 1960 (Pastores; Devonish; Cardoso, 2017).
} 
do ensino técnico concomitante ao ensino médio, a forma integrada (ensino médio e técnico em um único curso) e, ainda, a forma sequencial aos quem já possuíssem o ensino médio.

$\mathrm{O}$ CEFEF/RJ surgiu associado ao ensino profissionalizante e se confunde com a história da Educação Profissional desse país. Essa Instituição cresceu e se transformou ao longo de seus cento e três anos até chegar à atual configuração, com oferta de ensino de nível médio/técnico ao doutorado. Das ações iniciais aos dias de hoje, a construção histórica e social dessa Instituição de ensino operou-se na dinâmica do desenvolvimento do país, assumindo a tecnologia como objeto de interesse filosófico e científico, tendo como missão precípua promover a educação profissional mediante atividades de ensino, pesquisa e extensão que assegurem de modo reflexivo e crítico, a formação integral de profissionais que possam contribuir para o desenvolvimento científico, cultural, tecnológico e econômico da comunidade, conforme descrito em seu Plano de Desenvolvimento Institucional ( $\mathrm{PDI}^{3}, 2015$ 2019).

Nesse contexto histórico, o CEFET tem adquirido importante responsabilidade na formação dos trabalhadores, principalmente por fornecer a base teórica e técnica para atuar no mundo do trabalho, e nessa busca por uma qualificação não restrita aos conhecimentos formais. Na concordância com Ramos (2002), trabalhamos com o conceito de qualificação enquanto dimensão social, ao estabelecer uma relação dialética entre os saberes e a configuração da divisão social e técnica de trabalho, ou seja, reconhece que a qualificação está inserida numa dinâmica social. Na relação entre educação, trabalho e atualidade o CEFET ocupa lugar central no processo de obtenção do conhecimento e se consolida em um importante espaço de formação autônoma e política, onde as habilidades adquiridas não são apenas para o mero adestramento do "saber fazer".

\subsection{Os instrumentos da memória}

Le Goff (1990, p. 462) destaca que “o verbo monere significa fazer recordar donde avisar, iluminar, instruir. O monumentum é . . tudo aquilo que pode evocar o passado, perpetuar a recordação . . . ligar-se ao poder de perpetuação, voluntária ou involuntária, das

3 CEFET/RJ- Plano de Desenvolvimento Institucional - 2015-2019. Rio de Janeiro: CEFET, RJ, 2016. Disponível no endereço http://www.cefet-rj.br/attachments/article/97/PDI\%2020152019_versa\%CC\%83o\%20final\%20revisada\%20(2).pdf 
sociedades históricas.” A produção da memória pode ser concebida de diversas formas como, por exemplo, atos escritos, símbolos, troféus, uma obra comemorativa. Na reconstrução da história da Instituição, destacamos a celebração dos seus 100 anos de existência no dia 11 de agosto de 2017 e para homenagear a data, a Casa da Moeda do Brasil lançou uma medalha comemorativa em que, no seu anverso foi cunhada a fachada da Av. Maracanã e, em seu reverso, o símbolo do centenário do CEFET/RJ.

Figura 4 - Medalha lançada pela Casa da Moeda do Brasil para a comemoração dos 100 anos do CEFET/RJ.

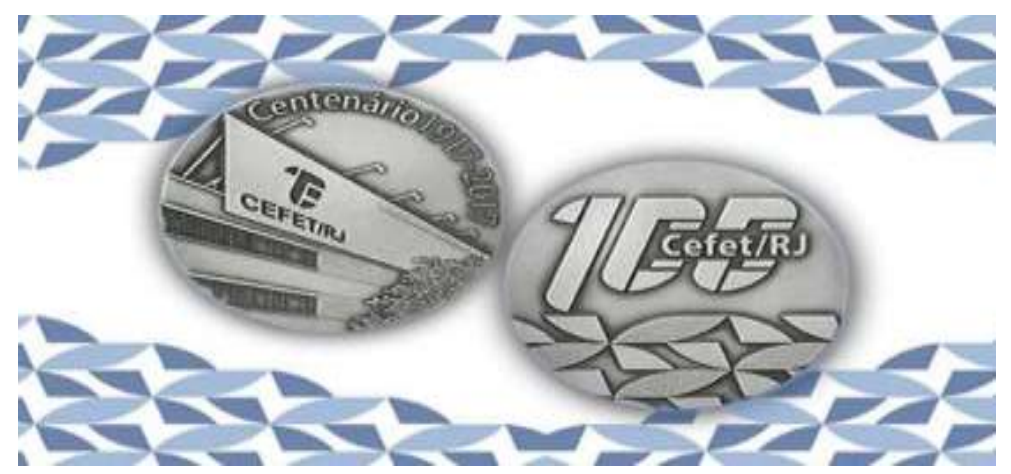

Fonte: Registro de uma Instituição Centenária CEFET/RJ (Pastore; Devonish; Cardoso, 2017).

A Associação dos ex-alunos do Centro Federal de Educação Tecnológica e Escola Técnica (AEA-CEFETN) criada em 1987, se constitui de outro mecanismo na perpetuação da memória da Instituição. Segundo Oliveira (2017), a associação publica mensalmente um jornal intitulado Informativo- Associação de Ex-Alunos do CEFET/RJ e da Escola Técnica Nacional. Editado desde a fundação da entidade, um dos pontos de destaque do periódico são as "Memórias da ETN", a celebração de datas comemorativas da escola, as lembranças e os obituários dos ex-alunos. Dessa forma, a Associação dos ex-alunos se traduz em um suporte para as relações sociais em que a memória é o foco central nessa sociabilidade. 
Figura 5 - Símbolo da Associação dos Ex-alunos do CEFET/RJ e Escola Técnica Nacional.

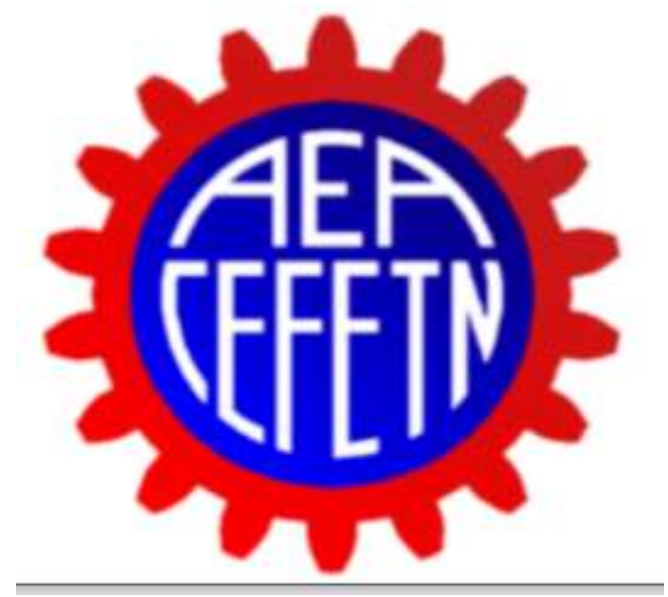

Fonte: http://www.aeacefetn.org.br/índex.htm

Sendo assim, a identidade que o CEFET e seus professores, gestores, servidores e alunos constroem é um processo dinâmico, sujeito a reformulação, às vivências e relações que se estabelecem, e para que sejam capazes de reafirmar essa identidade "é preciso que conheçam e compreendam a sua história, que reconstituam e preservem a sua memória . . . reconhecerem-se como sujeitos sociais coletivos com uma história e uma identidade própria a ser respeitada" (Ciavatta, 2005, p.13).

\section{A Implantação das Unidades de Ensino Descentralizadas (UnEDs)}

Figura 6 - Sistema CEFET/RJ com seus oito campi.

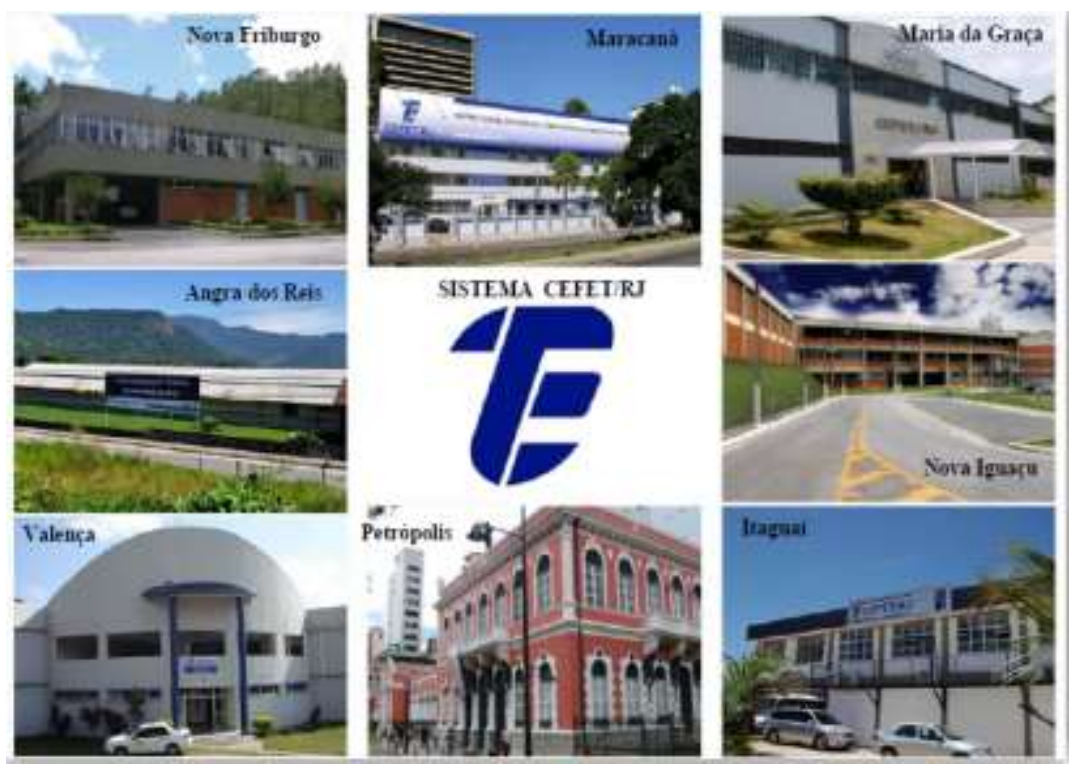

Fonte: PDI (2015-2019). 
Research, Society and Development, v. 9, n. 10, e2819108428, 2020

(CC BY 4.0) | ISSN 2525-3409 | DOI: http://dx.doi.org/10.33448/rsd-v9i10.8428

Ao aderir ao Plano de Expansão da Rede Federal de Educação Profissional e Tecnológica o CEFET/RJ passou a contar com Diversas Unidades de Ensino Descentralizadas (UnED) ou seja, com diversos campi no estado do Rio de Janeiro. A primeira UnED inaugurada foi a da cidade de Nova Iguaçu, em agosto de 2003, em seguida a do bairro de Maria da Graça, em junho de 2006. Em 2008 foi a vez da UnED da cidade de Petrópolis, no mês de setembro e em dezembro do mesmo ano, a UnED da cidade de Nova Friburgo. Em 2010, foram inaugurados a UnED da cidade de Itaguaí , a UnED da cidade de Valença e a UnED da cidade de Angra dos Reis. Todos os campi oferecem cursos de Ensino Técnico, de Graduação e de Pós-Graduação.

Conforme apresentado no Plano de Desenvolvimento da Instituição (PDI), a implantação do sistema multicampi, no período de 2005-2009, implicou em ações de organização administrativa orientada pelo estatuto aprovado pela Portaria Ministerial $\mathrm{n}^{\circ}$ 3.796, de $1^{\circ}$ de novembro de 2005. Além disso:

Permitiu o permanente diálogo do CEFET/RJ com o MEC, com representantes dos governos estadual, municipal e com empresas pública e privadas, visando à concretização de campi orientados pelo conceito de cidade-polo, com objetivo de aproveitar o potencial de desenvolvimento, a proximidade com arranjos produtivos locais, a possibilidade de parcerias e de infraestrutura existente (PDI 2015/2019, p.14).

\section{A Implantação do CEFET/Nova Friburgo}

Figura 7 - Sede do CEFET/Nova Friburgo.

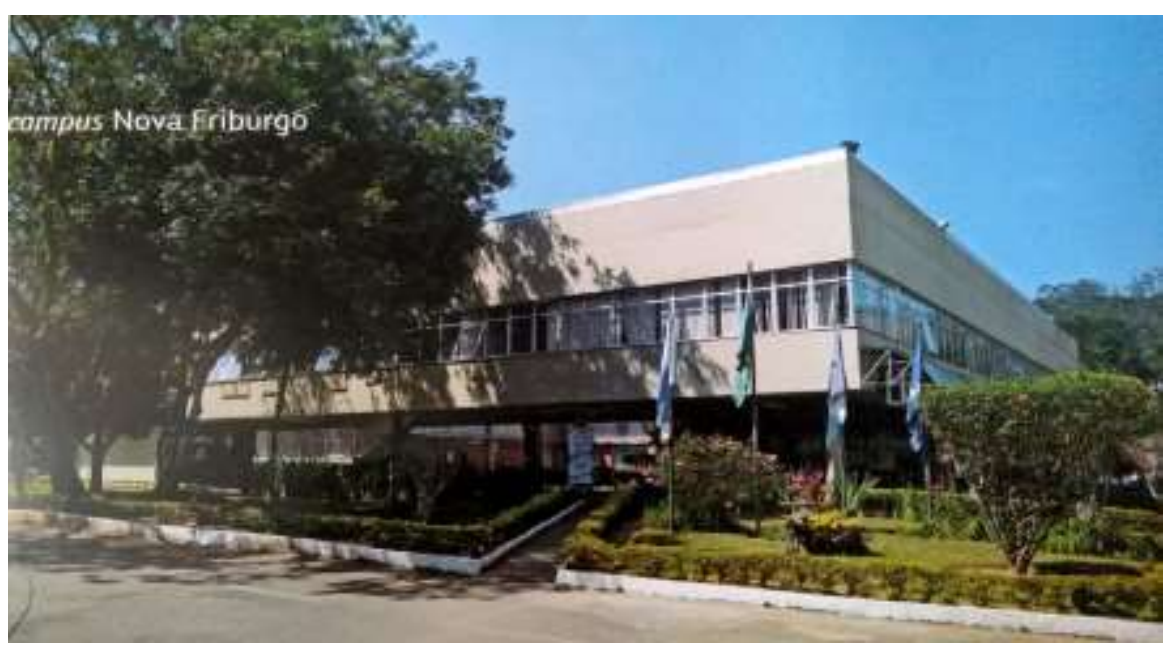

Fonte: Registro de uma Instituição Centenária (Pastore; Devonish; Cardoso, 2017). 
O CEFET/RJ campus Nova Friburgo entrou em operação em 17 de agosto de 2008, sendo formalmente inaugurado em 04 de dezembro do mesmo ano. Para concretização do projeto de implantação do campus somaram esforços do governo Federal, através do edital de Projeto de Apoio ao Plano de Extensão da Rede Federal de Educação Profissional e Tecnológica, do governo do Estado do Rio de Janeiro, pela cessão de uso do imóvel pertencente à Fundação do Departamento de Estradas de Rodagem do Rio de Janeiro (DERRJ), com condição necessária para instalação da infraestrutura para abrigar o corpo de servidores, alunos e empresas terceirizadas, além de equipamentos de sala de aula, administração e laboratório e da Prefeitura Municipal de Nova Friburgo com o apoio a realização de benfeitorias no imóvel.

As ações da Prefeitura foram realizadas junto a diversos órgãos setoriais que compõem a estrutura administrativa e acadêmica da entidade, para a elaboração e implantação do projeto de fundação do campus Nova Friburgo, levando em conta o conjunto de municípios que integram a região Centro- Norte Fluminense, a fim de contribuir para alavancar o desenvolvimento da região, pela proximidade com Arranjos Produtivos Locais (APL) no fomento a formação de parcerias e aproveitamento da infraestrutura existente.

Como uma das instituições orientadas pelo conceito de cidade-polo, o campus Nova Friburgo oferece atualmente o Curso Técnico de Informática e o Curso Técnico de Administração, iniciado em fevereiro de 2020, e no Nível Superior o Bacharelado em Sistemas de Informação, Engenharia Elétrica, Licenciatura em Física e o Curso Superior de Tecnologia em Gestão de Turismo, além dos cursos de Pós-Graduação lato sensu em Modelagem Matemática na Educação e em Turismo Sustentável. ${ }^{4}$

A vinda do CEFET para Nova Friburgo, além de proporcionar um ensino de qualidade e excelência à região nos diversos segmentos que atua, tem a disponibilidade de ofertar a seus alunos atividades complementares às quais muitos não teriam acesso, como participar em eventos em outros municípios/estados, projetos de extensão e são oferecidos também auxílios estudantis como a bolsa alimentação e bolsas de monitoria.

Com o objetivo de proporcionar uma visão geral do CEFET campus Nova Friburgo, no que diz respeito a sua estrutura organizacional e sua comunidade acadêmica, nos apoiaremos nas informações contidas no Plano de Desenvolvimento Institucional do CEFET/RJ (PDI) para o período 2015 a 2019 por expressar a identidade da Instituição e fornecer um extenso panorama da situação institucional.

\footnotetext{
${ }^{4}$ cefet-rj.br/índex.php/campus-nova-friburgo-historico
} 
Research, Society and Development, v. 9, n. 10, e2819108428, 2020

(CC BY 4.0) | ISSN 2525-3409 | DOI: http://dx.doi.org/10.33448/rsd-v9i10.8428

O PDI é um instrumento de planejamento e gestão elaborado por um período de cinco anos, onde se propõe às diretrizes pedagógicas, bem como a sua estrutura organizacional e às atividades acadêmicas, além de elencar previsões e projetos futuros, o documento viabiliza também o aprimoramento do conhecimento interno e externo da instituição (PDI, 2015-2019, p.6).

Os dados expressos nos Quadros 1, 2, 3 e 4 apresentam a composição e evolução do corpo discente do Ensino Superior e Técnico, do corpo docente e do corpo técnico administrativo do CEFET campus Nova Friburgo, realizada pelo Departamento de Recursos Humanos (DRH) no período de 2016 a 2019 e presentes no PDI da Instituição.

Quadro 1 - Distribuição do corpo Docente do CEFET/ NF.

\begin{tabular}{|l|c|c|c|}
\hline Unidade & Quantitativo- 2016 & Quantitativo-2017 & Quantitativo-2018 \\
\hline Nova Friburgo & 55 & 56 & 62 \\
\hline
\end{tabular}

Fonte: DRH, dez/ 2016, dez/ 2017, dez/ 2018

O aumento do quantitativo do quadro docente e do corpo técnico administrativo do CEFET/NF se deve à abertura de diversos concursos com a participação direta desses segmentos.

Quadro 2 - Distribuição do corpo discente (quantidade alunos por curso) do Ensino Técnico, da Graduação e Pós Graduação do CEFET/NF em 2018.

\begin{tabular}{|c|c|c|}
\hline CEFET /NF & Cursos & $\mathrm{N}^{\circ}$ Alunos \\
\hline \multirow{2}{*}{$\begin{array}{c}\text { Técnico integrado ao } \\
\text { Médio }\end{array}$} & Técnico de Informática & 115 \\
\hline & Total & 115 \\
\hline \multirow{4}{*}{ Graduação } & Superior de Tecnologia & 149 \\
\hline & Bacharelado & 401 \\
\hline & Licenciatura & 91 \\
\hline & Total & 641 \\
\hline \multirow{4}{*}{ Pós Graduação Lato Sensu } & Turismo Sustentável & 14 \\
\hline & $\begin{array}{c}\text { Modelagem Matemática na } \\
\text { Educação }\end{array}$ & 9 \\
\hline & Total & 23 \\
\hline & Total Geral & 779 \\
\hline
\end{tabular}

Fonte: Relatório de Gestão do Exercício de 2018, Fev/2019. 
Research, Society and Development, v. 9, n. 10, e2819108428, 2020

(CC BY 4.0) | ISSN 2525-3409 | DOI: http://dx.doi.org/10.33448/rsd-v9i10.8428

Quadro 3 - Distribuição do corpo Técnico Administrativo do CEFET/NF.

\begin{tabular}{|l|c|c|c|}
\hline Unidade & Quantitativo- 2016 & Quantitativo-2017 & Quantitativo-2018 \\
\hline Nova Friburgo & 26 & 30 & 30 \\
\hline
\end{tabular}

Fonte: DRH, dez/ 2016, dez/2017, dez/ 2018

Quadro 4 - Distribuição do corpo Técnico-Administrativo por cargo do CEFET/NF em 2018.

\begin{tabular}{|l|c|}
\hline \multicolumn{1}{|c|}{ Cargo } & Quantitativo-2018 \\
\hline Administrador & 5 \\
\hline Assistente em Administração & 2 \\
\hline Assistente de Alunos & 1 \\
\hline Arquivista & 1 \\
\hline Assistente social & 3 \\
\hline Auxiliar em Administração & 1 \\
\hline Bibliotecário-Documentalista & 2 \\
\hline Pedagogo/Área & 1 \\
\hline Psicólogo/Área & 2 \\
\hline Técnico Assuntos Educacionais & 1 \\
\hline Técnico de Tecnologia da Informação & $\mathbf{3 0}$ \\
\hline Técnico em Eletrônica & 1 \\
\hline Técnico em Secretariado & \\
\hline Total Geral & \\
\hline
\end{tabular}

Fonte: DRH dez/2018.

\subsection{A Extensão no CEFETcampus Nova Friburgo como aliada do ensino e da pesquisa}

A extensão junto ao ensino e a pesquisa constitui objetivo institucional do CEFET, pelo compromisso de divulgação e produção de conhecimentos em resposta a demandas da 
sociedade. E, em se tratando de grupos da população cujas necessidades básicas ainda não foram atendidas, a extensão do campus Nova Friburgo assume a responsabilidade social de utilização desse conhecimento a serviço da melhoria de condições da qualidade de vida dessa população ${ }^{5}$.

O programa de extensão Centro de Educação de Linguagens (CELi) que acontece no CEFET/RJ campus Nova Friburgo desde 2009, visa ao oferecimento de cursos regulares na área de línguas adicionais abertos à comunidade interna e externa à instituição de maneira gratuita, com foco na formação geral e crítica do aprendiz. De cunho educacional, tal projeto está centrado no ensino de línguas adicionais (projetos de Língua Alemã, projetos de Língua Inglesa, projetos de Língua Espanhola e projetos de Línguas Surdas).

No apoio educacional às pessoas com deficiência visual, destacamos o projeto de extensão "Olhos meus", que está vinculado ao Programa CELi com o objetivo de promover a inclusão de aluno com deficiência visual e, para isso, utiliza diversas estratégias e ferramentas, tais como a Tutoria de Pares que consiste em capacitar e fornecer Ledores para os alunos de escolas públicas com deficiência visual e que precisam do auxílio de um ledor para estudar.

Figura 8 - Centro de Educação e Linguagens do CEFET campus Nova Friburgo (CELi).
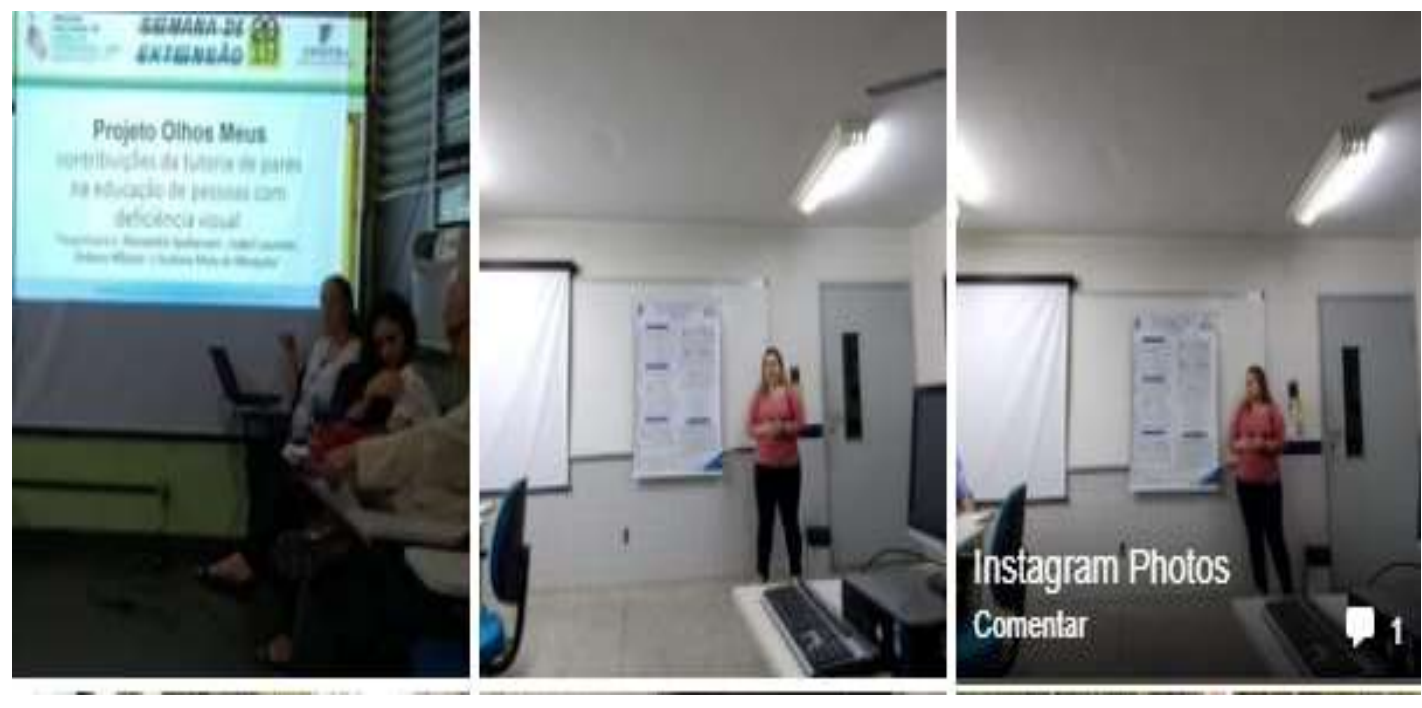

${ }^{5}$ Cefet-rj.br/índex.php/apresentação-extensao 

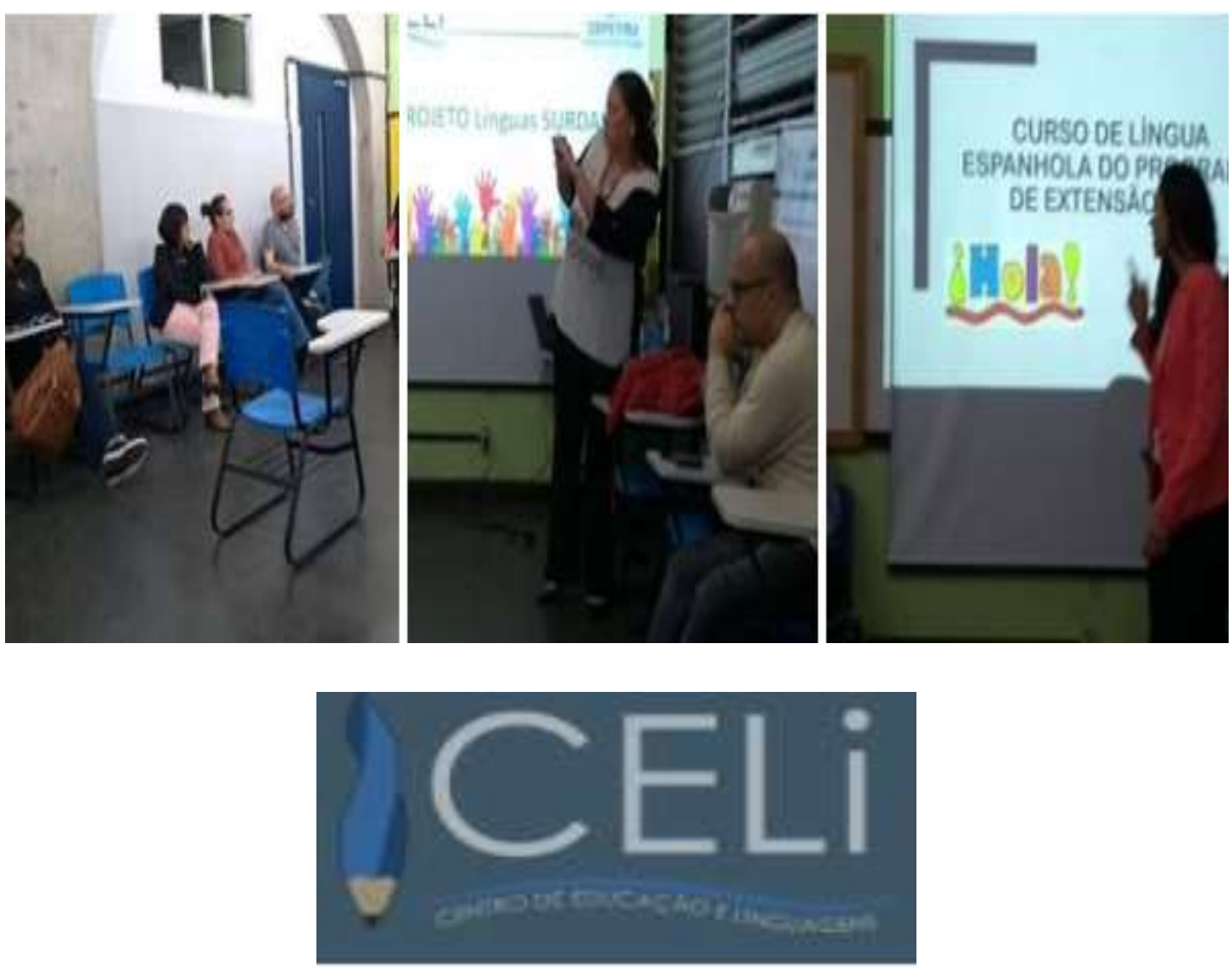

Fonte: celi.cefet-rj.r.

Na Figura 8 são apresentadas diferentes atividades desenvolvidas pelo programa de extensão do Centro de Educação e Linguagens (CELi).

\subsection{CEFET campus Nova Friburgo e a promoção do desenvolvimento da região}

O CEFET/NF com sua oferta de cursos técnicos na forma integrada ao Ensino Médio, nas Licenciaturas, Bacharelado e Especializações voltadas principalmente para pesquisa aplicada de inovação tecnológica, tem contribuído para inclusão social e para o desenvolvimento econômico e social da região.

O site de notícias Nova Friburgo em foco - Portal de Notícias de Nova Friburgo e Região traz a matéria "CEFET de Nova Friburgo atende 800 alunos e ganha homenagem" (16 de agosto de 2017) ${ }^{6}$ onde destaca a importância de formar profissionais nas áreas associadas

\footnotetext{
${ }^{6}$ Nova Friburgo em Foco - coluna do Nader com Paulo Nader. Disponível em: https://www.novafriburgoemfoco.com.br/noticia/cefet-de-friburgo-atende-800-alunos-eganha-h. Acesso em 16/08/2020.
} 
às potencialidades regionais. Outra reportagem editada pelo site do jornal A Voz da Serra em 30 de agosto de 2019 aponta a seguinte notícia: "Graduação do CEFET em Friburgo entre as melhores do Brasil". A notícia faz alusão ao Bacharelado em Sistemas de Informação oferecido pelo CEFET/NF que vem se consolidando junto ao meio acadêmico e ao mercado de trabalho como um dos melhores em sua área de conhecimento em todo território nacional. Paralelamente, logo na primeira avaliação do Exame Nacional de Desempenho de Estudante (ENADE), os alunos do curso de Sistema de Informação obtiveram a nota máxima, que numa escala de 1 a 5 , alcançaram a nota 5 equivalente ao conceito "excelente"”.

Na dinâmica do desenvolvimento regional, o papel do CEFET/NF na formação profissional dos alunos da região é um grande ponto para minimizar a falta de profissionais qualificados e do trabalho informal, promovendo um ensino de qualidade com a preocupação de uma formação humana aliada à formação técnica para superar a redução da preparação para o trabalho não só no seu aspecto operacional, mas na busca para garantir uma formação integral do trabalhador para leitura de mundo e sua inserção na sociedade como cidadão capaz de ser produtivo, crítico e autônomo intelectualmente. Uma visão que englobe a técnica, mas que vá além dela incorporando aspectos que contribuam para uma perspectiva de superação do modelo de desenvolvimento econômico vigente, como Ramos (2008, p.03) expressa: "uma concepção de formação humana com base na integração de todas as dimensões da vida no processo formativo".

\section{Considerações Finais}

Ao resgatarmos alguns dos muitos momentos históricos pelos quais passou o CEFET/RJ, percebemos que sua trajetória tem sido marcante para o cenário da Educação Profissional e Tecnológica no Brasil.

A história institucional se confunde com as histórias de servidores e alunos, que juntos constroem de forma coletiva a excelência de uma instituição com suas tradições e costumes como Le Goff (1990, p.466) destaca: “a história faz-se com palavras, signos, paisagens. . . .

\footnotetext{
${ }^{7}$ A reportagem na íntegra se encontra no site do jornal A Voz da serra. Disponível em: https://avozdaserra.com.br//noticias/graduacao-do-ce. Acesso em 17/08/20020.
} 
Com tudo o que, pertencendo ao homem depende do homem, serve ao homem, expressa o homem, demonstra a presença, a atividade, os gostos e as maneiras de ser do homem.”

O CEFET campus Nova Friburgo constitui-se como uma instituição promovedora de um ensino público, profissional e tecnológico de qualidade para a formação de profissionais e para o desenvolvimento econômico e social do estado do Rio de Janeiro. A relevante atuação no processo educativo remete à constante reflexão sobre o tipo de educação que se pretende oferecer, bem como, o compromisso pelo equilíbrio entre tradição e inovação tão necessária para que o campus Nova Friburgo continue o seu processo de transformação e, dessa forma, qualificar profissionais dotados de sólida formação geral e educação profissional para atuarem num mundo crescentemente impactado pela vertente tecnológica e para o exercício da cidadania crítica.

Discorrer sobre a importância de uma educação pública de qualidade na região conforme exposto no presente trabalho, será significativo para o olhar dos pesquisadores, da população e dos dirigentes, porque amplia as possibilidades econômicas locais, além de facilitar o acesso cada vez maior de jovens ao ensino superior e técnico. O impacto de uma Instituição como o CEFET instalado na região é enorme, seja no uso de sua tecnologia e na produtividade da economia local, seja no incentivo no campo cultural e social.

\section{Referências}

Brandão, M. (2009). CEFET Celso Suckow e algumas transformações históricas na formação profissional. Trabalho Necessário. 9(7).

Candau, J. (2011). Busca memorial e patrimonialização. In: Memória e identidade. (Maria Letícia Ferreira, Trad.). São Paulo: Contexto.

Cardoso, T. F. L. (2000). A Formação Docente na Escola Normal de Artes e Ofícios Wenceslau Braz. I Congresso Brasileiro de História da Educação. Recuperado de http://www.sbhe.org.br/novo/congressos/cbhe1/anais/154_tereza_m.pdf

Cardoso, T. F. L. (2005). O Papel Social da Escola Normal de Artes e Ofícios Wenceslau Braz. XXIII Simpósio Nacional de História. Londrina, Paraná, Brasil, 1. Recuperado de https://anpuh.org.br/uploads/anais-simposios/pdf/2019-01/1548206573_88f90db3452fd 47da223053182bf9cd6.pdf 
Ciavatta, M. (2005). A Formação Integrada à escola e o trabalho como lugares de memória e identidade. Revista Trabalho necessário. 3(3). Rio de Janeiro.

Ciavatta, M. (2004). Educando o trabalhador da "grande família da fábrica": a fotografia como fonte histórica. In: Ciavatta, M., Alves, N. (Orgs.), A leitura de imagens na pesquisa social: história, comunicação e educação. São Paulo: Cortez.

Dias, D. de O. (1973). Estudo documentário e histórico sobre a Escola Técnica Federal Celso Suckow da Fonseca. Rio de Janeiro: CEFET/RJ.

Le Goff, J. (1990). História e memória (Bernardo Leitão, et al. Trad.). São Paulo, Campinas: UNICAMP.

Lei $n^{\circ}$ 4.759, de 20 de agosto de 1965. Dispõe sobre a denominação e qualificação das Universidades e Escola Técnicas Federais. Brasília. Recuperado de http://www.planalto.gov.br/ccivil_03/leis/1950-1969/L4759.htm

Lei $n^{\circ}$ 4.127, de 25 de fevereiro de 1942. Estabelece as bases de organização da rede federal de estabelecimentos de ensino industrial. Recuperado de https://www2.cama ra.leg.br/legin/fed/declei/1940-1949/decreto-lei-4127-25-fevereiro-1942-414123publicacaooriginal-1-pe.html

Lei $n^{\circ}$ 181, de 17 de fevereiro de 1967. Dá nova denominação à atual Escola Técnica Federal da Guanabara. Recuperado de https://www2.camara.leg.br/legin/fed/declei/19601969/decreto-lei-181-17-fevereiro-1967-375916-publicacaooriginal-1-pe.html

Medeiros, J. B. (2000). Redação Científica: A prática de fichamentos, resumos, resenhas (4a ed.). São Paulo: Atlas.

Minayo, M. C. de S. (2010). O desafio do conhecimento: pesquisa qualitativa em saúde. (12a ed.). São Paulo: Hucitec- Abrasco. 
Oliveira, S. S. R. de. (2017). A história do CEFEF-RJ na memória da associação de exalunos. XII Encontro regional sudeste de historia oral. Recuperado de http://www.sudeste2017.historiaoral.org.br/resources/anais/8/1507844397_ARQUIVO_OLIV EIRA,Samuel.HistoriadoCefet-RJ_paraosite.pdf

Pastores, D. H., Devonish, I. M. S., Cardoso, T. F. L.(2017). Registros de uma instituição centenária: Cefet/RJ Centro Federal de Educação Tecnológica Celso Suckow da Fonseca. (p.120). Rio de Janeiro: CEFET/RJ.

Ramos, M. N. (2008, maio). Concepção do Ensino Médio integrado à Educação Profissional. Seminário promovido pela Secretaria de Educação do Estado do Pará. Pará, Brasil. Recuperado de http://forumeja.org.br/go/sites/forumeja.org.br.go/files/concepc ao_do_ensino_medio_integrado5.pdf

Ramos, M. N. (2002). A educação profissional pela pedagogia das competências e a superfície dos documentos oficiais. 23(80), 401-422. Campinas: Edu. Soc.

Ricoeur, P. (2007). A memória, a história, o esquecimento. (Alain François, et al. Trad.). Campinas: UNICAMP.

\section{Porcentagem de contribuição de cada autor no manuscrito}

Júlia Cristina Eyer de Mello - 50\%

Marta Ferreira Abdala Mendes - 50\% 